\title{
Trace metals in surface sediments of the Taiwan Strait: geochemical characteristics and environmental indication
}

\author{
Xuelu Gao ${ }^{1,2}$ - Fengxia Zhou ${ }^{2}$ Hon-Kit Lui ${ }^{1}$. Jiann-Yuh Lou ${ }^{3}$. \\ Chen-Tung Arthur Chen ${ }^{1}$ • Wen Zhuang ${ }^{4}$
}

Received: 19 August 2015 / Accepted: 20 October 2015 /Published online: 30 October 2015

(C) Springer-Verlag Berlin Heidelberg 2015

\begin{abstract}
The concentration and geochemical fractionation of six trace metals related with environmental quality assessment, namely $\mathrm{Cd}, \mathrm{Cr}, \mathrm{Cu}, \mathrm{Ni}, \mathrm{Pb}$, and $\mathrm{Zn}$, in 30 surface sediments from both inshore and offshore areas of the Taiwan Strait were measured to investigate their distribution characteristics, evaluate their potential mobility, and assess their pollution status. The geoaccumulation index results indicated that, on average, the studied metals presented an order of $\mathrm{Cd}>\mathrm{Pb}>\mathrm{Ni}>\mathrm{Zn}>\mathrm{Cu}>\mathrm{Cr}$ and were practically in uncontaminated status except $\mathrm{Cd}$. The results of the sequential extraction analysis indicated that, on average, the studied metals were mostly accumulated in residual fraction except $\mathrm{Cd}$ whose concentration was the highest in the acid soluble fraction presenting a high risk to the environment, and their mobility decreased in the sequence of $\mathrm{Cd}>\mathrm{Pb}>\mathrm{Ni}>\mathrm{Cu}>\mathrm{Zn}>\mathrm{Cr}$. Based on the mean probable effect level quotients, the combination of the studied metals had an $8 \%$ probability of being toxic at
\end{abstract}

Responsible editor: Philippe Garrigues

Chen-Tung Arthur Chen

ctchen@mail.nsysu.edu.tw

Xuelu Gao

xlgao@yic.ac.cn

1 Department of Oceanography, National Sun Yat-sen University, Kaohsiung 804, Taiwan

2 Key Laboratory of Coastal Environmental Processes and Ecological Remediation, Yantai Institute of Coastal Zone Research, Chinese Academy of Sciences, Yantai, Shandong 264003, China

3 Department of Marine Science, Naval Academy, Tsoying, Kaohsiung 813, Taiwan

4 College of City and Architecture Engineering, Zaozhuang University, Zaozhuang, Shandong 277160, China two sampling sites and had a $21 \%$ probability of being toxic at the rest of sites. The spatial distribution of the studied metals in total concentrations and different geochemical fractions corroborated the previous findings about the possible sediment transportation routes in and around the Taiwan Strait.

Keywords Sequential extraction - Chemical fractionation . Environmental assessment $\cdot$ Marginal sea $\cdot$ Marine pollution

\section{Introduction}

Scientists have made great efforts to understand the biogeochemical cycles of trace metals in the marine environment because many of them are critical for marine life and therefore influence the functioning of ocean ecosystems (e.g., Anderson et al. 2014). However, certain trace metals needed by organisms as micronutrients may be toxic at elevated concentrations or availability and then they turn into environmental pollutants. Therefore, many marine coastal areas in the world are suffering from the negative impacts of trace metals because of the excessive input of them by massive human activities (e.g., Sundaray et al. 2011; Pan and Wang 2012; Naser 2013; Gao et al. 2014). So, the marine biogeochemical function of trace metals is of apparent contradiction. The fact that sediments accumulate the external environmental impacts makes them an essential source for the information acquisition in major marine monitoring programs. To understand the concentrations and distributions of trace metals in the environment is a fundamental precondition for the effective management of their pollution.

The Taiwan Strait is in the southernmost part of the East China Sea (ECS) with an area of $\sim 8 \times 10^{4} \mathrm{~km}^{2}, 370 \mathrm{~km}$ in length, and $180 \mathrm{~km}$ in width on average, and the water depth in most parts of the Taiwan Strait is less than $60 \mathrm{~m}$. It separates 
the Taiwan island from the Chinese mainland but connects the ECS with the South China Sea (SCS) (Fig. 1). It transports large amounts of heat, waters, and nutrients between the ECS and the SCS (Chen and Wang 1999; Chung et al. 2001; Chen and Sheu 2006; Hu et al. 2010). Although exhibiting obvious seasonal variations, briefly, the western part of the Taiwan Strait is occupied by the Zhejiang-Fujian Coastal Current, and the eastern part of the Strait is occupied by the water of the SCS and a branch of the Kuroshio Current (Jan et al. 2002; Han et al. 2013). Both sides of the Taiwan Strait are areas densely populated with vibrant human activities.

Previous reports about trace metals in sediments mostly aimed at local or regional sites in the coastal areas of the Taiwan Strait (e.g., Fang and Hong 1999; Hung et al. 2001; Chen and Selvaraj 2008; Chung et al. 2011; Lin et al. 2014). In this research, surface sediments from both inshore and offshore locations covering most areas of the Taiwan Strait were measured to investigate the spatial distributions of the concentrations and fractionations of six trace metals, i.e., $\mathrm{Cd}, \mathrm{Cr}, \mathrm{Cu}$, $\mathrm{Ni}, \mathrm{Pb}$, and $\mathrm{Zn}$, that relate to the environmental quality assessment, estimate their potential mobility, and assess the degree of contamination and the ecological risks of these metals to the environment.

\section{Materials and methods}

\section{Sampling}

The field survey of this study was carried out in April 2008 on board the R/V Ocean Researcher I (Cruise No. 861). The samples used in this research were the top 5-cm sediments collected from 30 locations in the Taiwan Strait (Fig. 1) using a gravity corer. Sites 1 and 2 were located near the estuary of the Tsengwen River; sites 10, 29, and 30 were located near the estuaries of the Choshui, Tanshui, and Tachia Rivers, respectively. The samples were stored at $\sim 4{ }^{\circ} \mathrm{C}$ in the dark until further analysis.

\section{Analytical methods}

Once transferred to the land-based laboratory, the samples were homogenized and oven-dried at $50{ }^{\circ} \mathrm{C}$; before which, the chunks of shells and other impurities distinguishable with the naked eyes were removed from the samples. Then, a portion of each sample was ground to pass a 200-mesh nylon sieve.

To obtain the total concentration of each studied metal, an aliquot of every ground sample was digested with the mixture of concentrated $\mathrm{HF}, \mathrm{HNO}_{3}$, and $\mathrm{HClO}_{4}(5: 2: 1)$. The sequential extraction method applied in this research to obtain the information about the fractionations of metals in the sediment samples was reported by Rauret et al. (1999) and successfully used in our previous studies (Gao et al. 2010, 2015a, b; Gao and Chen 2012; Gao and Li 2012; Zhuang and Gao 2014b). Four operationally defined geochemical fractions were identified by this scheme: acid soluble (fraction 1), reducible (fraction 2 ), oxidizable (fraction 3), and residual (fraction 4). The detailed sequential extraction protocol has been described by Gao et al. (2010). The concentrations of metals in the residual fractions were calculated by subtracting the metal concentrations of the first three steps of the sequential extraction from

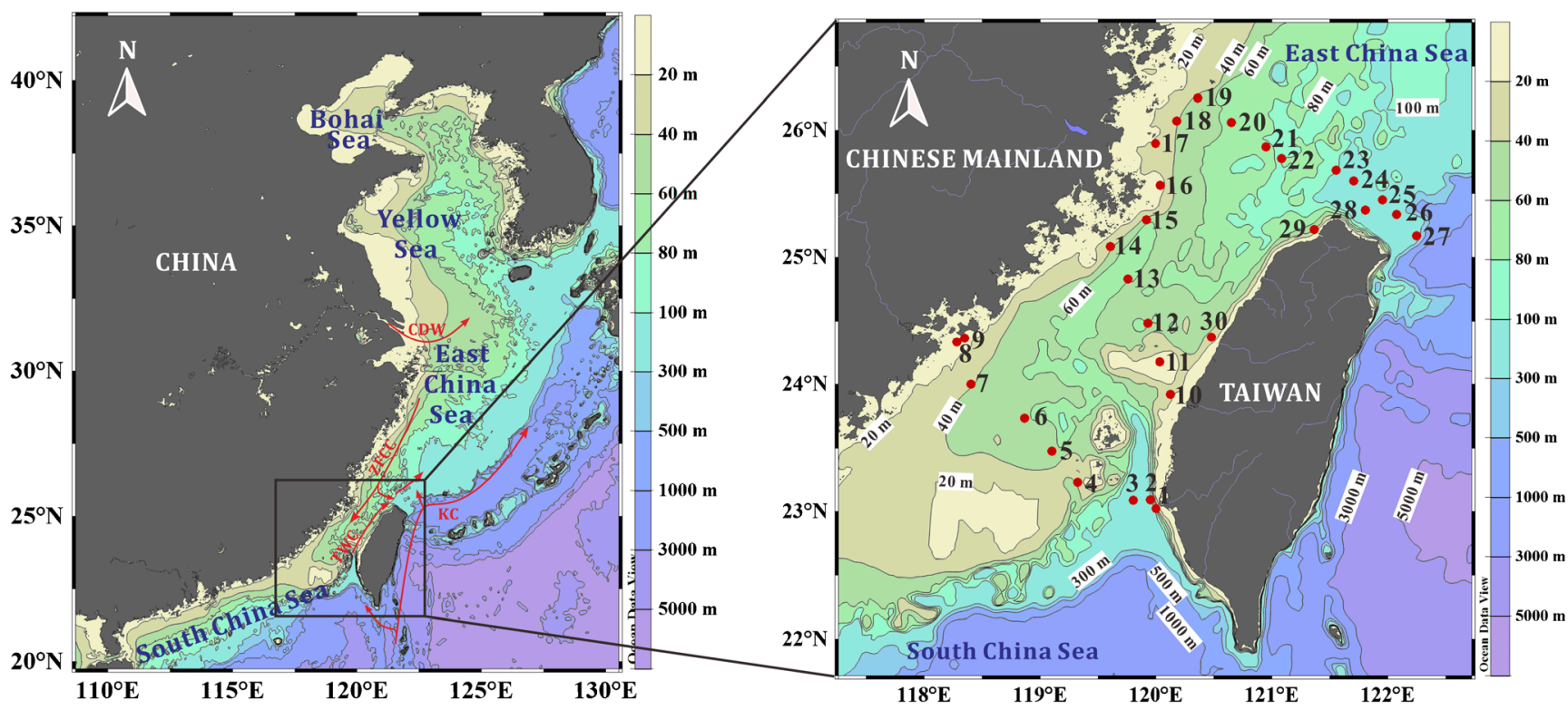

Fig. 1 Locations of sampling sites in the Taiwan Strait. The major currents in the East China Sea are schematically showed. CDW, ZFCC, $T W C$, and $K C$ represent the Changjiang Diluted Water, the Zhejiang-

Fujian Coastal Current, the Taiwan Warm Current, and the Kuroshio Current, respectively. It should be noticed that the current system in the East China Sea has great seasonal variations 
the total digestion measurements. To validate the applicability of this calculation, two randomly selected residues from the third step of the extraction procedure were digested by the same method as that used in the total digestion measurements, and the measured metal concentrations in them were 86$104 \%$ of their corresponding values obtained by calculating the difference between the results of the total digestion measurements and the sums of the results of the acid soluble, reducible, and oxidizable fractions.

The concentrations of $\mathrm{Cd}, \mathrm{Cr}, \mathrm{Cu}, \mathrm{Pb}, \mathrm{Ni}$, and $\mathrm{Zn}$ were determined by the inductively coupled plasma mass spectrometry (PerkinElmer ELAN DRC II). We used the Chinese national reference material of GBW-07333 and GBW-07314 to control the analytical quality. The results were consistent with the reference values and the differences were all within $10 \%$. All plastic and glassware were precleaned by soaking in $10 \%$ $\mathrm{HNO}_{3}(v / v)$ for at least 2 days, followed by soaking and rinsing with deionized water. All chemicals used in the experiment were guaranteed reagent grade. Blank determinations were carried out for each set of analysis using the same reagents. All data were corrected for dry weight of the sample. Careful operation was performed to reduce potential contamination in all procedures.

\section{Results and discussion}

\section{Metals in total concentrations}

The spatial variations of the studied metals are shown in Fig. 2 and the related information is summarized in Table 1. The studied metals in total concentrations were found to vary greatly with sites. For example, although sites 8 and 9 had the shortest distance between each other, the concentrations of the studied metals at site 9 were $~ 1.5-5.9$ times of those at site 8 . The recorded values were the lowest at site 5 in the middle of the south transect (sites 1-9) for all metals except $\mathrm{Ni}$, whose value was the lowest at site 8 in the western part of the same transect near to the Xiamen Bay; the recorded values were the highest at site 13 in the middle transect (sites 10-14) for $\mathrm{Cd}$ and at site 27 in the north transect (sites 17-27) for $\mathrm{Pb}$, and they were the highest at sites 17-19 in the northwestern part of the study area for the rest of the metals.

The mean data indicated that the target metals in the surface sediments of the Taiwan Strait exhibited the following descending order: $\mathrm{Zn}>\mathrm{Cr}>\mathrm{Ni}>\mathrm{Pb}>\mathrm{Cu}>\mathrm{Cd}$. This was exactly the same as the order of their reported average concentrations in the sediment of the China Shelf Sea (Table 1). Among the studied metals, only the mean concentration of $\mathrm{Cr}$ was lower than its corresponding value in the sediment of the China Shelf Sea, and the reverse was true for the rest of the metals (Table 1).
As shown in Table 1, on the whole, the average concentrations of the studied metals in this study were comparable to the values reported for the surface sediments of the Liaodong Bay (Hu et al. 2013), the Laizhou Bay (Zhuang and Gao 2014b), and different areas of the Yellow Sea (Yuan et al. 2012; Li et al. 2013; Huang et al. 2014). They were significantly lower than the values reported for the surface sediments of the Jinzhou Bay in the Bohai Sea (Li et al. 2012), which is one of the most heavily polluted coastal region in China, and this is also the case when the results of this research were compared with those of the Quanzhou Bay (Yu et al. 2008) in the west side of the Taiwan Strait and the Kaohsiung Harbor (Chen et al. 2007) and the Dapeng Bay (Chung et al. 2011) in the east side of the Taiwan Strait. The values of $\mathrm{Cr}, \mathrm{Cu}$, and $\mathrm{Zn}$ in this study were apparently lower than the corresponding values reported for the surface sediments of the Changjiang Estuary intertidal zone (Zhang et al. 2009) and the NW East China Sea off the Changjiang Estuary (Yu et al. 2013) to the north of the Taiwan Strait, and the values of $\mathrm{Pb}$ and $\mathrm{Zn}$ were apparently lower than the corresponding values reported for the surface sediments of the Xiamen Bay (Lin et al. 2014) to the west of the south transect (sites 1-9).

Fluvial delivery is the most dominant land-to-ocean transportation way for sediments, as rivers contribute $95 \%$ of sediments to the ocean, most of which are deposited in coastal and marginal seas (Syvitski et al. 2003, 2005; Liu et al. 2009). River discharge is also a major pathway for a majority of anthropogenic pollutants into marine environments (Shahidul Islam and Tanaka 2004), and previous reports indicated that the lowermost reach of rivers and estuaries are usually characterized by higher enrichment of some trace metals in sediments (Gao and Chen 2012; Zhuang and Gao 2014a). So, as a general rule, the concentrations of trace metals in the bottom sediments of coastal waters would decrease seaward in the areas affected by high intensity of onshore human activities such as the Taiwan Strait. Consistent with this general feature, the concentrations of the studied metals showed an overall distribution trend of decreasing from both sides to the middle along the south transect, and meanwhile, they showed a gradually declining trend from the coast of the Chinese mainland to the coast of the Taiwan island along the middle transect (Fig. 2). However, besides the impact of sources, the spatial distribution of trace metals in marine sediments is the combined effects of a variety of environmental and biogeochemical factors including complicated hydrodynamic conditions and chemical and biological processes. This was perhaps the reason why the concentrations of some studied metals in the sediments from some inshore and/or estuarial sites were lower than those in the sediments from some offshore sites (Fig. 2).

Site 5 had the lowest metal concentrations perhaps mainly because the waters there are from the Kuroshio branch (Chen and Wang 2006; Hong et al. 2011; Qiu et al. 2011), which is of 
Fig. 2 The spatial variations of the total concentrations of each studied metal in the surface sediments of the Taiwan Strait. The TEL and PEL values of metals are indicated with dash lines
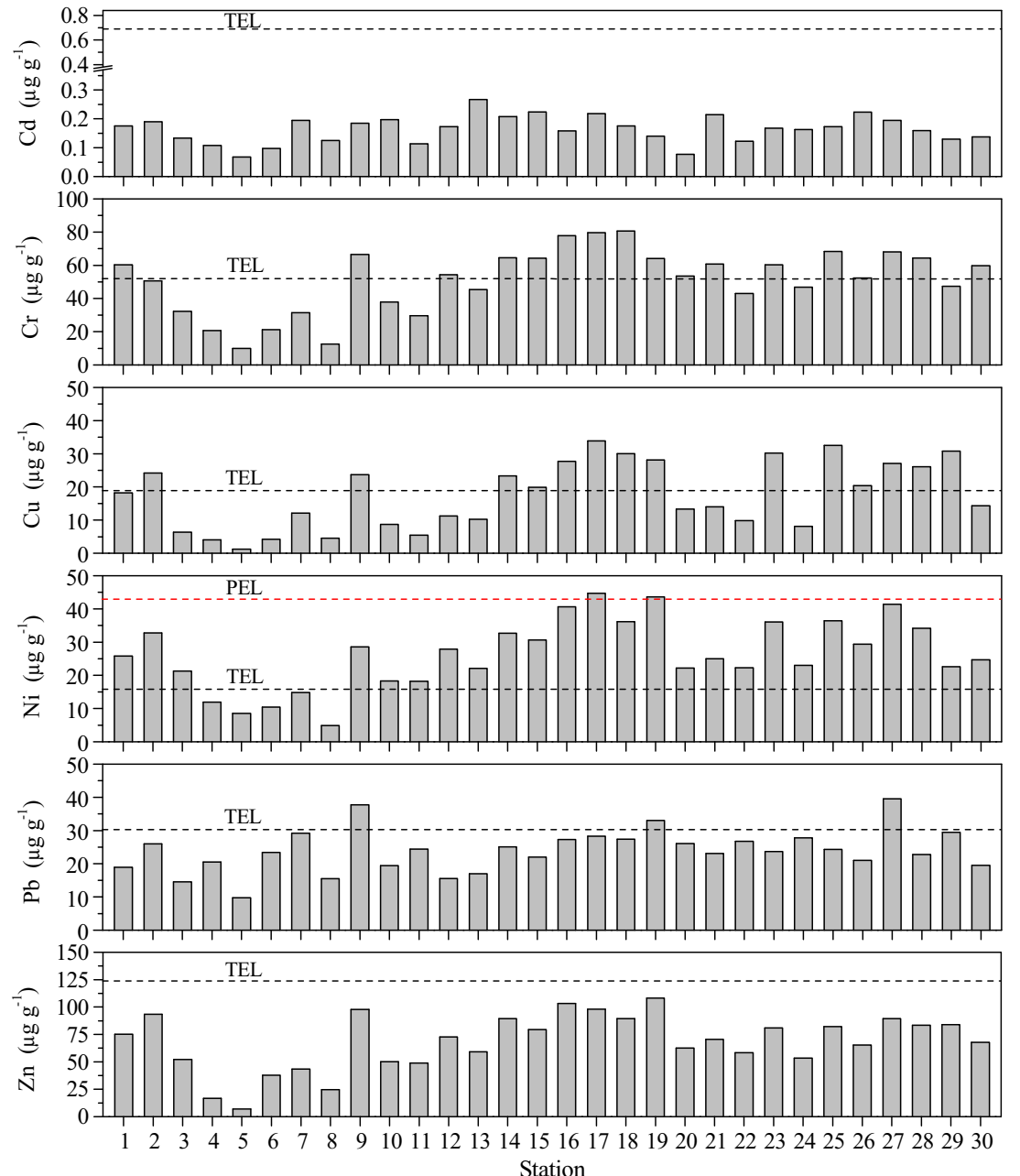

an open-ocean origin. Sites 1-4 are also affected by the Kuroshio branch but sediments from Taiwan played a major role (Liu et al. 2008a, b). Furthermore, the dumping of slags off SW Taiwan has increased the metal concentrations in sediments (Chen 2007; Selvaraj et al. 2010), and the movement of currents might bring those contaminated sediments northwards from there to the regions near sites 1 and 2 which will increase metal concentrations in their sediments to some extent. The high metal concentrations at site 9 should be attributed to the pollution from the watershed of the Jiulongiiang River and Xiamen.

Sites 19 to 14 showed the direction of the flow pattern in winter and after typhoons in summer (Han et al. 2013; He et al. 2014), and the metal concentrations in their sediments generally decreased southwards (Fig. 2). So, it was probably caused by the southward transport of the sediments from the Changjiang and Zhejiang provinces. The metal concentrations at some sites of 20 to 28 were generally in the higher parts of the ranges of metal concentrations recorded in this study. This might be owing to the pollution from western Taiwan as the flows are generally northward (Jan et al. 2002, 2006; Chen and Sheu 2006; Chen et al. 2010). Furthermore, southwardflowing China coastal currents frequently turn towards the east near $26^{\circ} \mathrm{N}$ (Jan et al. 2002, 2006; He et al. 2014), and this is probably another reason. The results of hierarchical cluster analysis, which will be discussed later in this section, also support the influence of these two reasons on the distribution pattern.

Like sites 20 to 28 , sites 10 to 14 were also in the direction away from the Chinese coast, while metal concentrations in their sediments generally decreased; this might be because China coastal currents do not generally move across the Taiwan Strait at this latitude (Jan et al. 2002, 2006), and pollution from the Chinese mainland is mainly trapped in the coastal region.

Studies have indicated that the suspended sediments transported by the Zhejiang-Fujian Coastal Current from the Changjiang Estuary in the north is the main source of the sediments in the western coast of the Taiwan Strait, and the suspended sediments transported by the small mountainous rivers from the Taiwan island are the main source of sediments in the eastern coast of the Taiwan Strait (Liu et al. 2008a, b; 


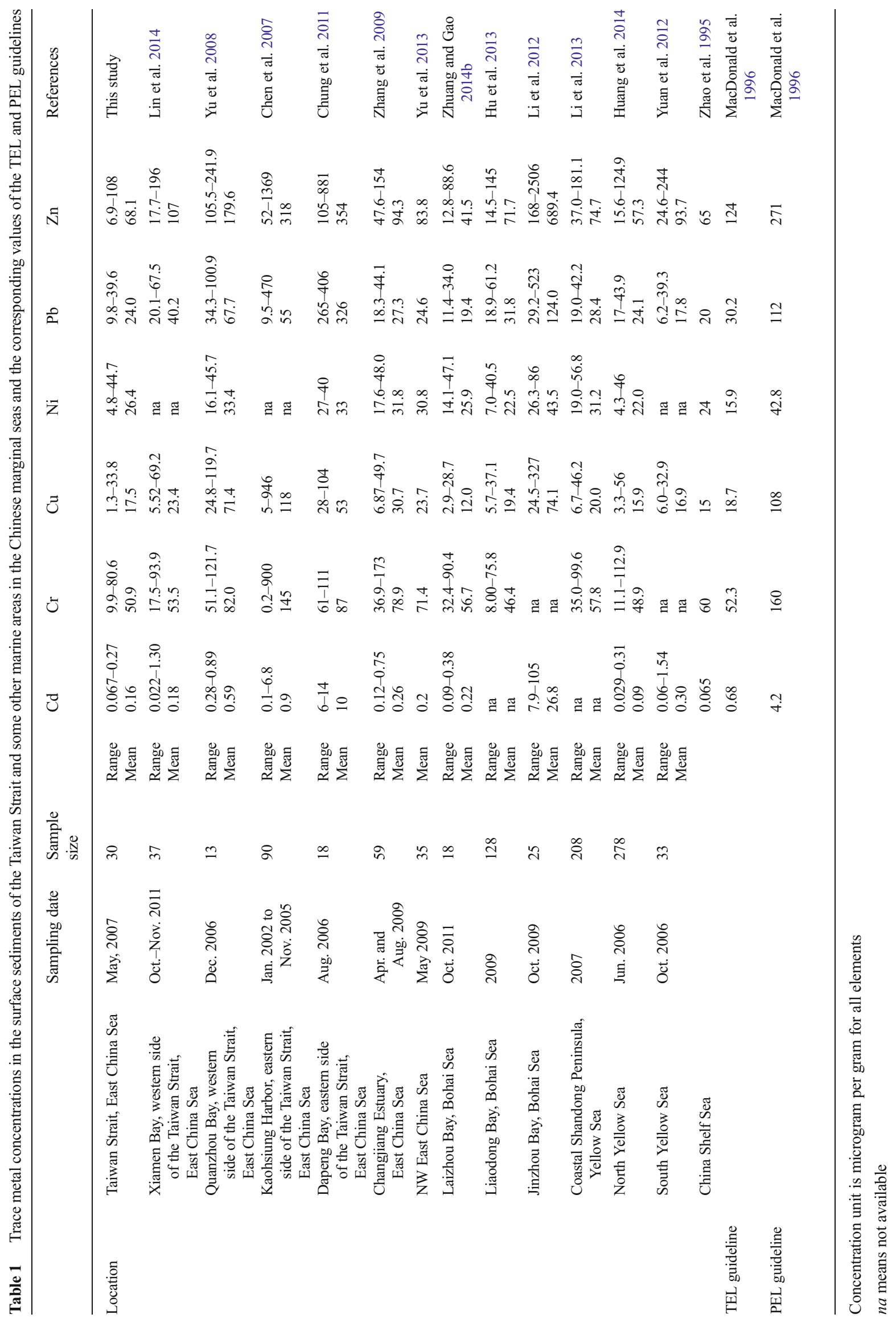


Hsu et al. 2014; Xu et al. 2014). It is speculated that much of fine mud delivered from the Taiwan island has been washed away by the local currents and escaped mainly northeastward with a proportion of it bypassing the northern Taiwan into the southern Okinawa Trough (Tseng and Shen 2003; Liu et al. 2008a). A latest report indicated that typhoon could cause the terrestrial material to transport from the coast of the Chinese mainland across the Taiwan Strait and reach the region off northeastern Taiwan, and these typhoon-induced terrestrial materials could then be transported into the southern Okinawa Trough along the western edge of the Kuroshio (He et al. 2014).

The hierarchical cluster analysis was performed based on the data of metals in total concentrations and the geochemical fractions determined which will be described in the following section. As shown in Fig. 3, our results indicated that the surface sediments from sites 23, 25, 27, and 28 in the northern and northeastern region off Taiwan had a strong similarity with those from sites 16-19 in the inshore area of the Chinese mainland. We considered this corroborated the findings of He et al. (2014) about the transportation of terrestrial material from the coast of the Chinese mainland to the region off the northeastern Taiwan. Meanwhile, the surface sediments from sites $23,25,27$, and 28 also showed a strong similarity with those from sites 29 and 30 near the estuaries of the Tachia and Tanshui Rivers, indicating another sediment-transporting route from the Taiwan island.

\section{Metal fractionation}

The results of the sequential extraction indicated that the studied metals took on different fractionation patterns (Fig. 4). On average, the percentages of $\mathrm{Cu}, \mathrm{Pb}$, and $\mathrm{Zn}$ in the four determined fractions took on the same order of fraction $4>2>3>1$, and the orders were fraction $1>4>2>3$ for $\mathrm{Cd}$, fraction $4>3>$ $2>1$ for $\mathrm{Cr}$, and fraction $4>3>1>2$ for $\mathrm{Ni}$.

Except for $\mathrm{Cd}$, the studied metals were dominantly retained in the residual fraction of the sediments, accounting for $\sim 50$ $90 \%$ of their respective total concentrations on average with a sequence of $\mathrm{Cr}(90 \%)>\mathrm{Zn}(79 \%)>\mathrm{Cu}(76 \%)>\mathrm{Ni}(73 \%)>$ $\mathrm{Pb}(50 \%)$; the mean percentage of $\mathrm{Cd}$ in this fraction was $30.2 \%$. The values of $\mathrm{Cd}$ were the highest in the acid soluble fraction with a mean value of $45 \%$; the values of the rest of the

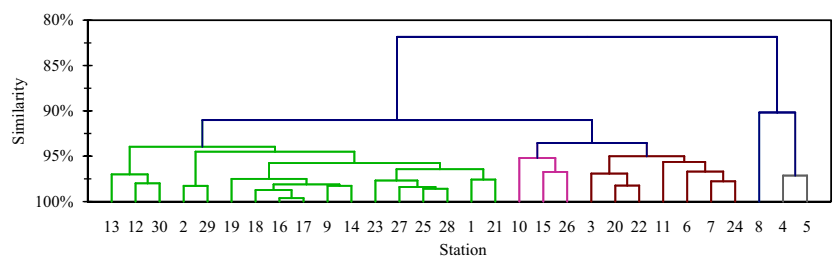

Fig. 3 Hierarchical dendrogram in terms of the sampling stations based on the data of metals in total concentrations and the geochemical fractions determined metals in this fraction, from high to low, were $8.8 \%$ for $\mathrm{Ni}$, $4.0 \%$ for $\mathrm{Zn}, 3.2 \%$ for $\mathrm{Cu}, 2.7 \%$ for $\mathrm{Pb}$, and $0.4 \%$ for $\mathrm{Cr}$ on average. Reducible fraction was the most abundant fraction of non-residual $\mathrm{Cu}, \mathrm{Pb}$, and $\mathrm{Zn}$, and oxidizable fraction was the most abundant fraction of non-residual $\mathrm{Cr}$ and $\mathrm{Ni}$. The average percentages of metals in reducible and oxidizable fractions followed the order of $\mathrm{Pb}(31.2 \%)>\mathrm{Cd}(17.4 \%)>\mathrm{Cu}$ $(12.8 \%)>\mathrm{Zn}(10.8 \%)>\mathrm{Ni}(7.5 \%)>\mathrm{Cr}(0.8 \%)$ and $\mathrm{Pb}$ $(16.4 \%)>\mathrm{Ni}(10.6 \%)>\mathrm{Cr}(8.7 \%)>\mathrm{Cu}(7.9 \%)>\mathrm{Cd}$ $(7.5 \%)>\mathrm{Zn}(6.3 \%)$, respectively. The general fractionation features of the studied metals in this research were similar to their distribution features in different geochemical phases obtained by the same sequential extraction method in the surface sediments of other Chinese coastal areas such as the Bohai Bay, the Laizhou Bay, and the Daya Bay (Gao et al. 2010; Gao and Chen 2012; Zhuang and Gao 2014b).

In addition to the abovementioned features, the fractionation patterns of $\mathrm{Cd}, \mathrm{Cu}$, and $\mathrm{Pb}$ showed a significant spatial variation (Fig. 4). The proportions of $\mathrm{Cd}$ in acid soluble, reducible, oxidizable, and residual fractions varied in the ranges of $24.8-61.3,3.6-34.4,1.6-17.7$, and $10.2-58.0 \%$ of its total concentrations in the sediments, respectively; the corresponding ranges were $0.3-12.1,5.6-20.6,2.8-15.6$, and 59.3$88.4 \%$ for $\mathrm{Cu}$ and $0.5-7.2,12.9-50.0,6.6-30.4$, and 24.5$79.4 \%$ for $\mathrm{Pb}$. Among the 30 sampling sites, only at two sites $\mathrm{Cd}$ in the residual fraction was higher than the sum of it in the non-residual fractions, and the number for $\mathrm{Pb}$ under this condition was 14.

\section{Pollution and risk assessment}

As described previously, both sides of the Taiwan Strait have been faced with intense human activities. Therefore, the biogeochemical features of trace metals in its sediments are a result of the joint natural and anthropogenic influences. Geoaccumulation index $\left(I_{\text {geo }}\right)$ proposed by Müller (1969) is one of the approaches that have been widely applied to separate the metal concentrations of natural variability from the fraction associating with sediments due to human activities:

$I_{\text {geo }}=\log _{2}\left(\frac{C_{\mathrm{n}}}{1.5 B_{\mathrm{n}}}\right)$

where $C_{\mathrm{n}}$ is the measured concentration of metal $n$ and $B_{\mathrm{n}}$ is the geochemical background concentration of metal $n$; the correction factor 1.5 is used to take into consideration possible differences in the background values due to lithological variation. The reported concentrations of the studied trace metals in the sediment of the China Shelf Sea, taken from Zhao et al. (1995) and shown in Table 1 , were used in the $I_{\text {geo }}$ calculation.

The geoaccumulation index defines seven classes sediment quality: $I_{\text {geo }} \leq 0$ (class 0 , practically uncontaminated); $0<I_{\text {geo }} \leq$ 1 (class 1 , uncontaminated to moderately contaminated); 1 
Fig. 4 The distributions of the studied metals in different geochemical fractions of the surface sediments from the Taiwan Strait. $N, L, M, H$, and $V$ in the top tick labels represent the metal had no risk, a low risk, a medium risk, a high risk, and a very high risk to the environment, respectively
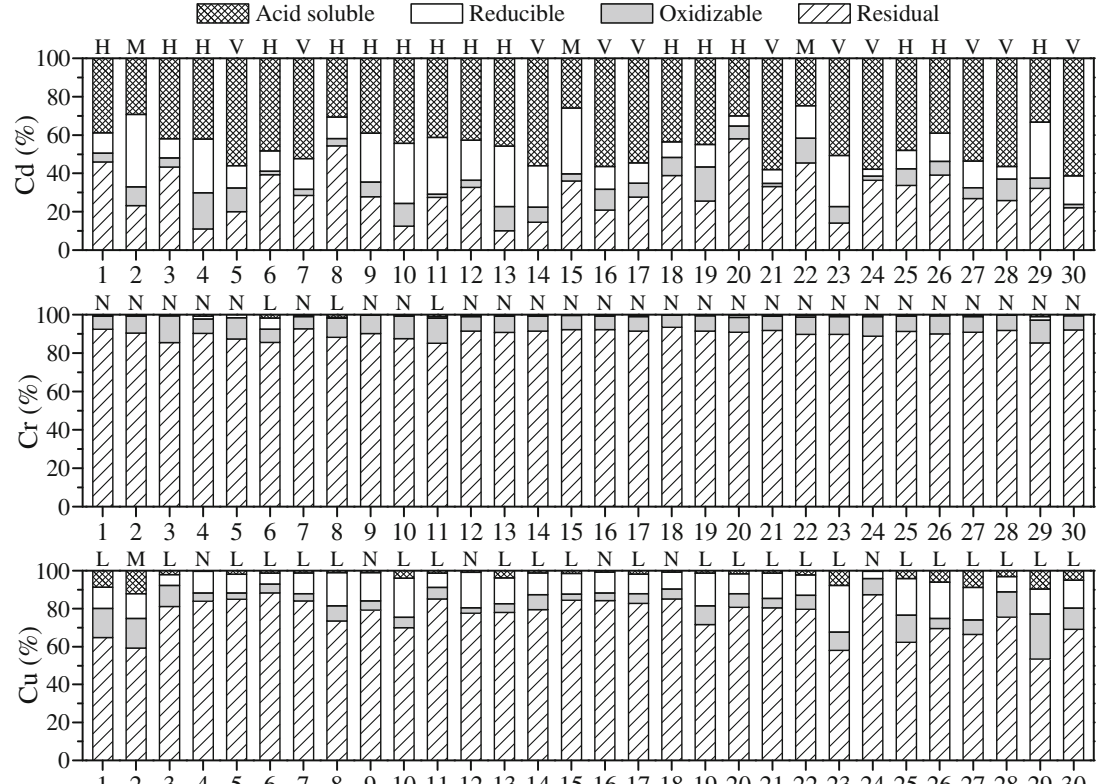

$122 \quad 3 \quad 4 \quad 5 \quad 6 \quad 7 \quad 8 \quad 9101112131415161718192021222324252627282930$

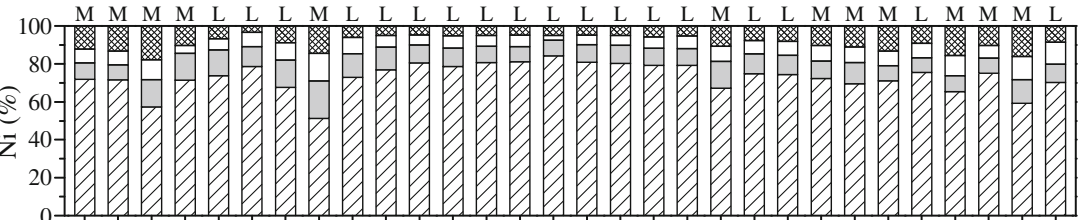

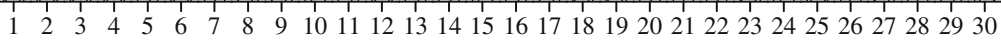

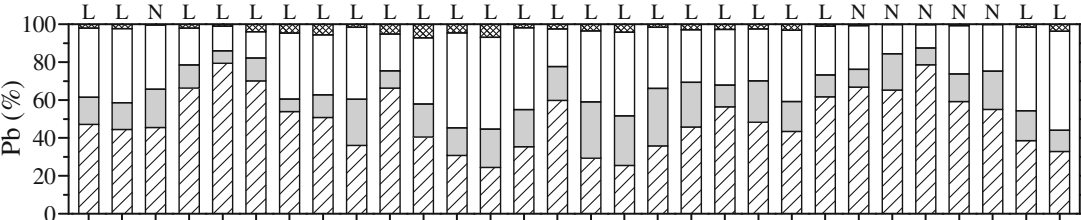

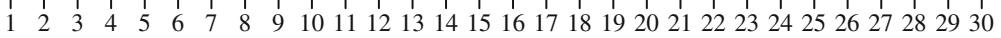

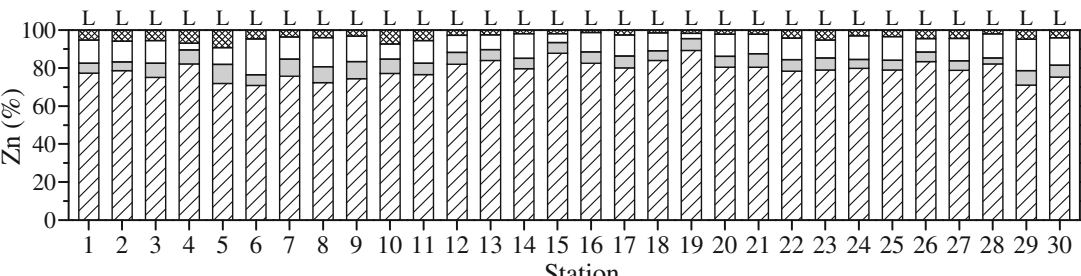
Station
$<I_{\text {geo }} \leq 2$ (class 2, moderately contaminated); $2<I_{\text {geo }} \leq 3$ (class 3 , moderately to heavily contaminated); $3<I_{\text {geo }} \leq 4$ (class 4 , heavily contaminated); $4<I_{\mathrm{geo}} \leq 5$ (class 5 , heavily to extremely contaminated); $5<I_{\text {geo }}$ (class 6 , extremely contaminated) (Müller 1969).

As shown in Fig. 5a, all of the studied metals except $\mathrm{Cd}$ had an $I_{\text {geo }}$ value of lower than 1 at all the sampling sites. Reflected by their average $I_{\text {geo }}$ values, Cd was more accumulated in the surface sediments of the Taiwan Strait than the other five metals, and the metals presented an order of $\mathrm{Cd}(0.68)>\mathrm{Pb}$ $(-0.37)>\mathrm{Ni}(-0.60)>\mathrm{Zn}(-0.68)>\mathrm{Cu}(-0.71)>\mathrm{Cr}(-0.97)$. The $I_{\text {geo }}$ values of $\mathrm{Cr}$ fell into the uncontaminated class at all the sampling sites, and this was also the condition of $\mathrm{Pb}$ except at sites 9, 19, and 27 and $\mathrm{Zn}$ except at sites 9, 16, 17, and 19
(Fig. 5a). The $I_{\text {geo }}$ values of $\mathrm{Cd}$ fell into the uncontaminated to moderately contaminated class at two thirds of the sampling sites, and they fell into the moderately contaminated class at seven of the sampling sites, namely 10,13-15, 17, 21 , and 26 , and fell into the uncontaminated class at only three of the sampling sites, namely 5,6 , and 20; The $I_{\text {geo }}$ values of $\mathrm{Cu}$ and $\mathrm{Ni}$ fell into the uncontaminated to moderately contaminated class at 12 and 7 of the 30 sampling sites, respectively (Fig. 5a). The $I_{\text {geo }}$ values also indicated that only one site, namely 19 , had five metals that were in the uncontaminated to moderately contaminated class, and seven sites, namely $9,16-18,23,25$, and 27 , had three or four metals that were in the uncontaminated to moderately contaminated class. 
Fig. 5 The spatial distribution of $I_{\text {geo }}($ a) and mean PEL quotient (b) values of the studied metals in the surface sediments from the Taiwan Strait. The solid lines indicate the positions of 0 and 1 in the top panel and 0.1 in the bottom panel
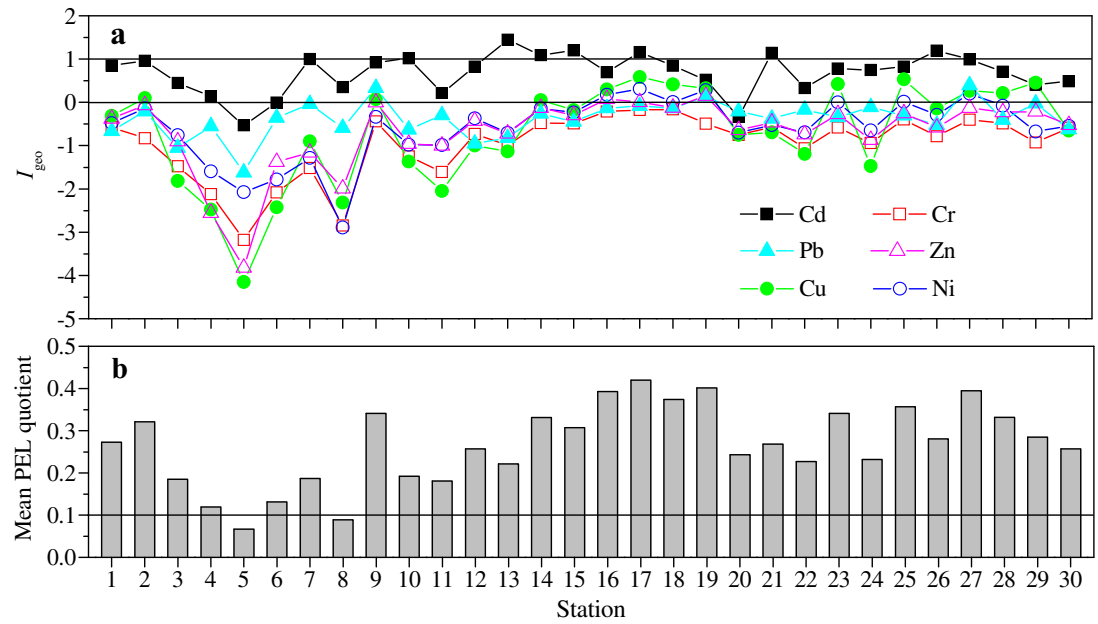

The information of $I_{\text {geo }}$ does not indicate potential biological harm associated with metal levels. Sediment quality guidelines (SQGs) have been developed to address this issue. One of the widely used SQGs is the threshold effects level (TEL) and probable effects level (PEL) values (MacDonald et al. 1996). For each metal studied in this research, there are a TEL and a PEL values available to deal with its environmental concerns in marine sediments and in response to regulatory programs (Table 1), and these two values define three concentration ranges of metals, including those that were rarely, occasionally, or frequently associated with adverse effects on biota (MacDonald et al. 1996).

As shown in Fig. 2, all the concentrations of $\mathrm{Cd}$ and $\mathrm{Zn}$ measured were lower than their corresponding TEL values, which mean that they could pose a limited risk of toxicity; that was also the condition of $\mathrm{Pb}$ except at three sites, i.e., sites 9,19 , and 27, where its concentrations were higher than its TEL value, although its concentrations at few sites were close to its TEL value. $\mathrm{Cr}$ and $\mathrm{Cu}$ showed a similar situation that their concentrations at about half of the sampling sites were higher than their TEL values but much lower than their PEL values, and that means they may occasionally cause adverse effects on biota in these sites. The concentrations of $\mathrm{Ni}$ at more than two thirds of the sampling sites were higher than its TEL value but lower than its PEL value; its concentrations at sites 17 and 19 were higher than its PEL value, which made it the only metal that may frequently cause adverse effects on biota.

The combined possible biological effects of the six studied metals could be evaluated by the mean PEL quotient method using the following formula:

mean PEL quotient $=\frac{\sum_{\mathrm{x}=1}^{n} \frac{C_{\mathrm{x}}}{P E L_{\mathrm{x}}}}{n}$

where $C_{\mathrm{x}}$ and $P E L_{\mathrm{x}}$ are the concentration of metal $x$ in sediment and its PEL value, respectively, and $n$ is the total number of metals (Long et al. 2000). The mean PEL quotients of $<0.1$ have an $8 \%$ probability of being toxic, the mean PEL quotients of $0.11-1.5$ have a $21 \%$ probability of being toxic, the mean PEL quotients of $1.51-2.3$ have a $49 \%$ probability of being toxic, and the mean PEL quotients of $>2.3$ have a $73 \%$ probability of being toxic (Long et al. 2000). As shown in Fig. 5b, in the surface sediments of the Taiwan Strait, the mean PEL quotients varied within the range of $0.12-0.42$ except at sites 5 and 8 indicating that the combination of the six studied metals may have a $21 \%$ probability of being toxic; the mean PEL quotients at sites 5 and 8 were 0.07 and 0.09 , respectively, indicating that the they may have an $8 \%$ probability of being toxic.

The TEL and PEL values are derived from the bulk concentrations of trace metals in sediments. In addition to their total concentrations, the geochemical fractionation of trace metals in sediments is equally important in the determination of their potential toxicity and threat to ecosystems (Quevauviller 1998; Sahuquillo et al. 2003). The mobility and bioavailability of metals in sediments and other solid geochemical samples are governed by the ways they bind with the matrix. The stronger they combine with sediment matrix means the less possibility they cause adverse effects on the environment.

It is reported that metals in non-residual fractions obtained from sequential extractions are more or less available to aquatic biota under certain conditions (Tack and Verloo 1995), among which the acid soluble fraction, namely the exchangeable and bound to carbonate components of sediments, is more weakly combined with the matrix than other fractions. This fraction may equilibrate with the aqueous phase and thus become more rapidly bioavailable and cause environmental toxicity (Karbassi and Shankar 2005).

A metal with no more than $1 \%$ of its total concentration in sediment existing as the acid soluble fraction is considered to have no risk to the environment; the percentage of the metal in the acid soluble fraction falling in the range of $1-10 \%$ indicates a low risk to the environment, its falling in the range of $10-30 \%$ indicates a medium risk to the environment, its 
falling in the range of $30-50 \%$ indicates a high risk to the environment, and the percentage being higher than $50 \%$ indicates a very high risk to the environment (Perin et al. 1985). According to this index, as shown in Fig. 4, Cd had a medium risk to the environment at three sites, it had a high risk to the environment at 16 sites, and it had a very high risk to the environment at the rest of the sites; $\mathrm{Cr}$ had a low risk to the environment at three sites 6,8 , and 11 , and it had no risk to the environment at the rest of the sites; $\mathrm{Cu}$ had a medium risk to the environment at site 2; it had no risk to the environment at six sites $4,9,12,16,18$, and 24 , and it had a low risk to the environment at the rest of the sites; Ni had a medium risk to the environment at 12 of the 30 sampling sites, and it had a low risk to the environment at the rest of 18 sites; $\mathrm{Pb}$ had no risk to the environment at six sites 3 and 24-28, and it had a low risk to the environment at the rest of the sites; $\mathrm{Zn}$ had no risk to the environment at all sites.

\section{Conclusions}

This study indicated that the surface sediments in the Taiwan Strait with higher concentrations of trace metals were mainly from the northwestern region of the Strait along the coast of the Chinese mainland. $\mathrm{Cd}$ was the most mobile element among the studied metals and its average percentage in the acid soluble fraction indicated it had a high risk to environment; the other metals were much less mobile compared with $\mathrm{Cd}$ and dominantly existed in the residual fraction. The spatial distribution of the concentration and fractionation of the studied metals might be an indication of the routes of sediment transportation in and around the Taiwan Strait.

According to their threshold effects level guidelines, the concentrations of both $\mathrm{Cd}$ and $\mathrm{Zn}$ could rarely pose a risk of toxicity on biota at all the sampling sites; this was also true for $\mathrm{Pb}$ at 27 of the 30 sampling sites and for $\mathrm{Cr}$ and $\mathrm{Cu}$ at about half of the sampling sites; the concentrations of $\mathrm{Cr}, \mathrm{Cu}$, and $\mathrm{Pb}$ might be occasionally associated with adverse effects on biota at the rest of the sampling sites; the concentrations of Ni might be rarely associated with adverse effects on biota at five sites, frequently associated with adverse effects on biota at two sites, and occasionally associated with adverse effects on biota at the rest of the sampling sites. The mean probable effects level quotients indicated that the concentrations of the studied metals might cause that 28 among the 30 surface sediments from the Taiwan Strait had a $21 \%$ probability of being toxic and the rest the two surface sediments had an $8 \%$ probability of being toxic.

Acknowledgments This study was co-supported by the Ministry of Science and Technology of Taiwan (MOST 103-2611-M-110-010, NSC 101-2611-M-110-010-MY3), the Taiwan's Aim for the Top University Program (04C030204), the Strategic Priority Research Program of the Chinese Academy of Sciences (XDA11020102), and the National Natural Science Foundation of China (41376083). The assistance of Ms. Hui
Gao in the sample preparation is greatly appreciated. Our thanks also go to three anonymous reviewers who provided constructive comments which helped improve the manuscript.

\section{References}

Anderson RF, Mawji E, Cutter GA, Measures CI, Jeandel C (2014) GEOTRACES: changing the way we explore ocean chemistry. Oceanography 27(1):50-61

Chen CTA (2007) Non-radioactive ocean pollution. In: Nihoul JCJ, Chen CTA (eds) Oceanography, vol 1. EOLSS Publishers, Oxford, pp 410-433

Chen CT, Selvaraj K (2008) Evaluation of elemental enrichments in surface sediments off southwestern Taiwan. Environ Geol 54:13331346

Chen CTA, Sheu DD (2006) Does the Taiwan warm current originate in the Taiwan Strait in wintertime? J Geophys Res 111:C04005

Chen CTA, Wang SL (1999) Carbon, alkalinity and nutrient budget on the East China Sea Continental Shelf. J Geophys Res 104:2067520686

Chen CTA, Wang SL (2006) A salinity front in the southern East China Sea separating the Chinese coastal and Taiwan Strait waters from Kuroshio waters. Cont Shelf Res 26:1636-1653

Chen CW, Kao CM, Chen CF, Dong CD (2007) Distribution and accumulation of heavy metals in the sediments of Kaohsiung Harbor, Taiwan. Chemosphere 66:1431-1440

Chen CTA, Jan S, Huang TH, Tseng YH (2010) Spring of no Kuroshio intrusion in the southern Taiwan Strait. J Geophys Res 115:C08011

Chung SW, Jan S, Liu KK (2001) Nutrient fluxes through the Taiwan Strait in spring and summer 1999. J Oceanogr 57:47-53

Chung CY, Chen JJ, Lee CG, Chiu CY, Lai WL, Liao SW (2011) Integrated estuary management for diffused sediment pollution in Dapeng Bay and neighboring rivers (Taiwan). Environ Monit Assess 173:499-517

Fang T-H, Hong E (1999) Mechanisms influencing the spatial distribution of trace metals in surficial sediments off the south-western Taiwan. Mar Pollut Bull 38:1026-1037

Gao XL, Chen CTA (2012) Heavy metal pollution status in surface sediments of the coastal Bohai Bay. Water Res 46(6):1901-1911

Gao XL, Li PM (2012) Concentration and fractionation of trace metals in surface sediments of intertidal Bohai Bay, China. Mar Pollut Bull 64(8):1529-1536

Gao XL, Chen CTA, Wang G, Xue QZ, Tang C, Chen SY (2010) Environmental status of Daya Bay surface sediments inferred from a sequential extraction technique. Estuar Coast Shelf Sci 86(3):369-378

Gao XL, Zhou FX, Chen CTA (2014) Pollution status of the Bohai Sea, China: an overview of the environmental quality assessment related trace metals. Environ Int 62:12-30

Gao XL, Zhou FX, Chen CTA (2015a) Trace metals in the suspended particulate matter of the Yellow River (Huanghe) estuary: concentrations, potential mobility, contamination assessment and the fluxes into the Bohai Sea. Cont Shelf Res 104:25-36

Gao XL, Zhuang W, Chen CTA, Zhang Y (2015b) Sediment quality of the SW coastal Laizhou Bay, Bohai Sea, China: a comprehensive assessment based on the analysis of heavy metals. PLoS ONE 10(3): e0122190. doi:10.1371/journal.pone.0122190

Han AQ, Dai MH, Gan JP, Kao SJ, Zhao XZ, Jan S, Li Q, Lin H, Chen CTA, Wang L, Hu JY, Wang LF, Gong F (2013) Inter-shelf nutrient transport from the East China Sea as a major nutrient source supporting winter primary production on the northeast South China Sea shelf. Biogeosciences 10:8159-8170

He XQ, Bai Y, Chen CTA, Hsin YC, Wu CR, Zhai WD, Liu ZL, Gong F (2014) Satellite views of the episodic terrestrial material transport to 
the southern Okinawa Trough driven by typhoon. J Geophys Res Oceans 119:4490-4504

Hong HS, Chen CTA, Jiang YW, Lou JY, Chen ZZ, Zhu J (2011) Source water of two-pronged northward flow in the southern Taiwan Strait in summer. J Oceanogr 67:385-393

Hsu F-H, Su C-C, Wang C-H, Lin S, Liu J, Huh C-A (2014) Accumulation of terrestrial organic carbon on an active continental margin offshore southwestern Taiwan: source-to-sink pathways of river-borne organic particles. J Asian Earth Sci 91:163-173

Hu JY, Kawamura H, Li CY, Hong HS, Jiang YW (2010) Review on current and seawater volume transport through the Taiwan Strait. J Oceanogr 66:591-610

Hu BQ, Li J, Zhao JT, Yang J, Bai FL, Dou YG (2013) Heavy metal in surface sediments of the Liaodong Bay, Bohai Sea: distribution, contamination and sources. Environ Monit Assess 185:5071-5083

Huang P, Li TG, Li AC, Yu XK, Hu NJ (2014) Distribution, enrichment and sources of heavy metals in surface sediments of the North Yellow Sea. Cont Shelf Res 73:1-13

Hung T-C, Meng P-J, Han B-C, Chuang A, Huang C-C (2001) Trace metals in different species of mollusca, water and sediments from Taiwan coastal area. Chemosphere 44:833-841

Jan S, Wang J, Chern CS, Chao SY (2002) Seasonal variation of the circulation in the Taiwan Strait. J Mar Syst 35:249-268

Jan S, Sheu DD, Kuo H-M (2006) Water mass and throughflow transport variability in the Taiwan Strait. J Geophys Res 112:C12012

Karbassi AR, Shankar R (2005) Geochemistry of two sediment cores from the west coast of India. Int J Environ Sci Technol 1:307-316

Li XY, Liu LJ, Wang YG, Luo GP, Chen X, Yang XL, Gao B, He XY (2012) Integrated assessment of heavy metal contamination in sediments from a coastal industrial basin, NE China. PLoS ONE 7: e39690

Li GG, Hu BQ, Bi JQ, Leng QN, Xiao CQ, Yang ZC (2013) Heavy metals distribution and contamination in surface sediments of the coastal Shandong Peninsula (Yellow Sea). Mar Pollut Bull 76(1-2): 420-426

Lin C, Liu Y, Li WQ, Sun XW, Ji WD (2014) Speciation, distribution, and potential ecological risk assessment of heavy metals in Xiamen Bay surface sediment. Acta Oceanol Sin 33(4):13-21

Liu JP, Liu CS, Xu KH, Milliman JD, Chiu JK, Kao SJ, Lin SW (2008a) Flux and fate of small mountainous rivers derived sediments into the Taiwan Strait. Mar Geol 256:65-76

Liu ZF, Tuo S, Colin C, Liu JT, Huang C-Y, Selvaraj K, Chen CTA, Zhao Y, Siringan FP, Boulay S, Chen Z (2008b) Detrital fine-grained sediment contribution from Taiwan to the northern South China Sea and its relation to regional ocean circulation. Mar Geol 255: $149-155$

Liu JP, Xue Z, Ross K, Wang HJ, Yang ZS, Li AC, Gao S (2009) Fate of sediments delivered to the sea by Asian large rivers: long-distance transport and formation of remote alongshore clinothems. Sediment Rec 7(4):4-9

Long ER, MacDonald DD, Severn CG, Hong CB (2000) Classifying the probabilities of acute toxicity in marine sediments with empiricallyderived sediment quality guidelines. Environ Toxicol Chem 19: 2598-2601

MacDonald DD, Scott Carr R, Calder FD, Long ER, Ingersoll CG (1996) Development and evaluation of sediment quality guidelines for Florida coastal waters. Ecotoxicology 5:253-278

Müller G (1969) Index of geoaccumulation in sediments of the Rhine River. GeoJournal 2:108-118

Naser HA (2013) Assessment and management of heavy metal pollution in the marine environment of the Arabian Gulf: a review. Mar Pollut Bull 72:6-13

Pan K, Wang WX (2012) Trace metal contamination in estuarine and coastal environments in China. Sci Total Environ 42:3-16

Perin G, Craboledda L, Lucchese L, Cirillo R, Dotta L, Zanette ML, Orio AA (1985) Heavy metal speciation in the sediments of Northern
Adriatic Sea: a new approach for environmental toxicity determination. In: Lekkas TD (ed) Heavy metal in the environment, vol 2. CEP Consultant, Edinburgh, pp 454-456

Qiu Y, Li L, Chen CTA, Guo XG, Jing CS (2011) Currents in the Taiwan Strait as observed by surface drifters. J Oceanogr 67:395-404

Quevauviller P (1998) Operationally defined extraction procedures for soil and sediment analysis I. Standardization. Trends Anal Chem 17(5):289-298

Rauret G, López-Sánche JF, Sahuquillo A, Rubio R, Davidson C, Ure A, Quevauviller PH (1999) Improvement of the BCR three step sequential extraction procedure prior to the certification of new sediment and soil reference materials. J Environ Monit 1:57-61

Sahuquillo A, Rigol A, Rauret G (2003) Overview of the use of leaching/ extraction tests for risk assessment of trace metals in contaminated soils and sediments. Trends Anal Chem 22(3):152-159

Selvaraj K, Parthiban G, Chen CTA, Lou JY (2010) Anthropogenic effects on sediment quality offshore southwestern Taiwan: assessing the sediment core geochemical record. Cont Shelf Res 30:12001210

Shahidul Islam M, Tanaka M (2004) Impacts of pollution on coastal and marine ecosystems including coastal and marine fisheries and approach for management: a review and synthesis. Mar Pollut Bull 48: 624-649

Sundaray SK, Nayak BB, Lin S, Bhatta D (2011) Geochemical speciation and risk assessment of heavy metals in the river estuarine sediments - a case study: Mahanadi basin, India. J Hazard Mater 186: 1837-1846

Syvitski JPM, Peckham SD, Hilberman R, Mulder T (2003) Predicting the terrestrial flux of sediment to the global ocean: a planetary perspective. Sediment Geol 162:5-24

Syvitski JPM, Vorosmarty CJ, Kettner AJ, Green P (2005) Impact of humans on the flux of terrestrial sediment to the global coastal ocean. Science 308:376-380

Tack FM, Verloo MG (1995) Chemical speciation and fractionation in soil and sediment heavy metal analysis: a review. Int J Environ Anal Chem 59:225-238

Tseng RS, Shen YT (2003) Lagrangian observations of surface flow patterns in the vicinity of Taiwan. Deep-Sea Res II 50:1107-1115

Xu YH, Sun QQ, Yi L, Yin XJ, Wang AJ, Li YH, Chen J (2014) The source of natural and anthropogenic heavy metals in the sediments of the Minjiang River Estuary (SE China): implications for historical pollution. Sci Total Environ 493:729-736

Yu R, Yuan X, Zhao Y, Hu G, Tu X (2008) Heavy metal pollution in intertidal sediments from Quanzhou Bay, China. J Environ Sci 20(6):664-669

Yu Y, Song JM, Li XG, Yuan HM, Li N (2013) Fractionation, sources and budgets of potential harmful elements in surface sediments of the East China Sea. Mar Pollut Bull 68:157-167

Yuan HM, Song JM, Li XG, Li N, Duan LQ (2012) Distribution and contamination of heavy metals in surface sediments of the South Yellow Sea. Mar Pollut Bull 64(10):2151-2159

Zhang WG, Feng H, Chang JN, Qu JG, Xie HX, Yu LZ (2009) Heavy metal contamination in surface sediments of Yangtze River intertidal zone: an assessment from different indexes. Environ Pollut 157: $1533-1543$

Zhao YY, Yan MC, Jiang RH (1995) Abundance of chemical elements in continental shelf sediment of China. Geo-Mar Lett 15:71-76

Zhuang W, Gao XL (2014a) Assessment of heavy metal impact on sediment quality of the Xiaoqinghe estuary in the coastal Laizhou Bay, Bohai Sea: inconsistency between two commonly used criteria. Mar Pollut Bull 83:352-357

Zhuang W, Gao XL (2014b) Integrated assessment of heavy metal pollution in the surface sediments of the Laizhou Bay and the coastal waters of the Zhangzi Island, China: comparison among typical marine sediment quality indices. PLoS ONE 9(4):e94145. doi:10. 1371/journal.pone.0094145 